\title{
Community involvement in the development of an environmental edu- cation programme: the Tswaing meteorite crater conservation area as a case study
}

\author{
C.H. SWANEPOEL, C.P. LoubSER and E.M.J.C. SCHALLER
}

\begin{abstract}
Swanepoel, C.H., C.P. Loubser and E.M.J.C. Schaller. 2004. Community involvement in the development of an environmental education programme: the Tswaing meteorite crater conservation area as a case study. Koedoe 47(1): 115-123. Pretoria. ISSN 00756458.
\end{abstract}

\begin{abstract}
A key requirement for the relevance of applied research in education is its actual impact on society. A case study was undertaken to determine how research insights could be implemented by involving a local community in the design and implementation of environmental education programmes in their environment. The Tswaing Meteorite Crater conservation area project was undertaken with the active participation of teachers, learners and education officers from the communities living around Tswaing, as well as subject specialists. Issues which should be considered in the development of similar programmes were also highlighted.
\end{abstract}

Key words: environmental education, community development, community involvement, rural development, environmental management, environmental ownership, preservation and utilisation, social sustainability.

C.H. Swanepoel, Institute for Educational Research, University of South Africa, P.O. Box 392, Unisa, 0003, South Africa; C.P. Loubser, Department of Further Teacher Education, University of South Africa; E.M.J.C. Schaller, Research fellow, Institute for Educational Research, University of South Africa.

\section{Introduction}

An issue which has often emerged and will probably always surface when research, especially in the human and social sciences, is the subject of discussion, is the way that research results are utilised for the benefit of human existence. This also applies to research regarding environmental education. An enormous expansion of knowledge concerning environmental education has occurred (Mosidi 1999). Moreover, environmental education literature tends to be loaded with noble statements such as 'A concern for the state of the environment and a looming environmental crisis [has] resulted in educators starting to teach with the environment as a focus' (Mosidi 1999) and 'it can be accepted that education had to move beyond teaching in and about the environment' (Viljoen 1993) to 'include education for the environment' (Fien 1993; Huckle 1991). In other words, knowledge, skills and attitudes must be simultaneously addressed in order to increase the community's awareness of the environment, to initiate actions to protect the environment in its totality and to achieve sustainable development within communities (Stevenson 1993; Republic of South Africa 1998). However, it is doubtful whether these ideals are actually realised in the daily life of citizens. Sustainability Education in European Primary Schools (SEEPS 1998) has, for example, pointed out that environmental education has failed in many cases and that the environmental crisis has worsened.

If the success of the implementation of environmental education is being questioned, then environmental educators should ask themselves what has been done with the knowledge and expertise gained in the past through international and local investigations. A further question deals with how this 
knowledge and expertise can be imparted successfully to communities of various age groups, contexts and cultures. In this regard, Smyth (1995) mentioned that environmental education calls for increased participation by communities in the management and development of the environment. In South Africa, society and the government are putting increasing pressure on environmental educators to transform this information into viable programmes within their respective communities or places of work (Republic of South Africa 1995; Neluvhalani \& Mphaphuli 2000). Therefore, as stated in the White Paper for Education and Training, there is an urgent need for all groups to become involved in the design, planning and implementation of environmental education programmes and projects (Republic of South Africa 1998).

With reference to the aforementioned exposition, the following research question was formulated:

How can environmental education knowledge be implemented by involving a local community in the planning and design of its own environmental education programmes

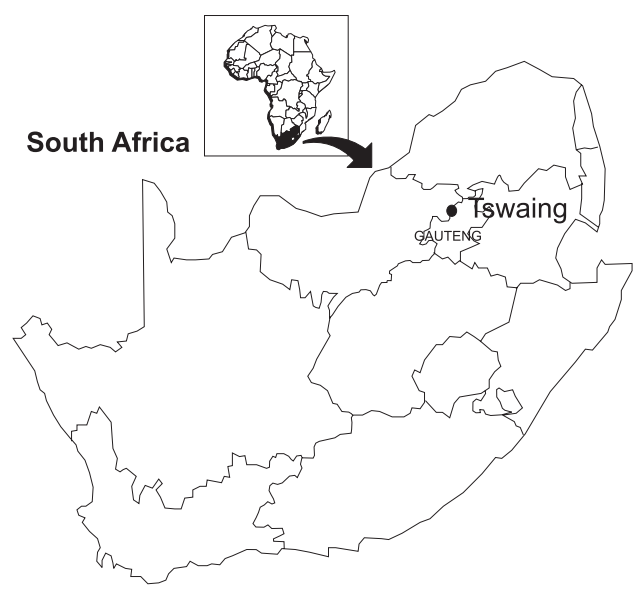

Fig.1. Tswaing Meteorite Crater's location in South Africa. and what are the important issues in this regard?

\section{Method}

The aim of the research was to address the research problem by conducting a case study in a particular local community. This was done by identifying a community (the cluster of communities living around the Tswaing Meteorite Crater in Soshanguve) and a specific environmental opportunity which could be utilised in the development of environmental education programmes; providing the community with an opportunity to become involved in developing outcomes-specific programmes for learners; and helping the community to discover the totality of their environment.

\section{Identifying a community}

There is no clear-cut definition for the term community. Many definitions are structured in an ecological sense and refer to animal communities, plant communities, etc. Defining the notion of 'human' communities is different and the specific definition depends on the context of a community. Khan (1994) gives an example in which a community was defined as the poor black people in an area in the United States of America and indicated that this group could also be a subgroup of other communities: town, country, state, black people, poor people and so forth. People tend to live differently in similar environments and differently at different times in the same environment (Bird 1989). It is, therefore, important for the researcher, facilitator and/or the community worker to define the target community. Once this has been done, such a person should be prepared to work with all the members/role players in the community (Khan 1994).

For the purpose of this research, the communities living around the Tswaing Meteorite Crater conservation area in Soshanguve were identified as the target community and are referred to as the Tswaing community. This community comprises areas of Winterveld, Soshanguve and Hammanskraal. Although these areas belong to the same larger geographic area and are characterised by poor living conditions, the inhabitants are diverse in the sense that they speak several different South African languages (English, Afrikaans, isiZulu, isiXhosa, SeSotho, SeTswana, etc.), each with its own cultural identity. The name Soshanguve, for example, originated from the language groups 
Sotho, Shangaan, Nguni and Venda. In this area, the environment and the use of natural resources and agriculture play an important role and influences the way of life. Many communities depend only on the environment for their existence. The houses are built from materials derived from the environment, food is obtained from the environment and the inhabitants work as farmers in the immediate environment. This relationship with the environment has been the topic of many projects. Furthermore, it has been established that poverty remains an alarming factor in other developing countries where this kind of relationship is dominant (Loubser 1998). Therefore, the Tswaing Meteorite Crater conservation area was identified with the aim of establishing how the environment could be utilised to the benefit of the surrounding communities. The research reported in this particular article focussed on adults and schools within communities in the larger Tswaing Meteorite Crater environment.

\section{Identifying an environmental opportunity}

The second phase in the research process was to identify an environmental opportunity which could be utilised in the development of environmental education programmes. The Tswaing Meteorite Crater conservation area was identified as suitable for this purpose. The Crater is a young, well-preserved impact crater within a largely uniform geological setting. It is of considerable international interest as a focus of future scientific research, as the sediment in the crater has a 160000 year record of climatic and environmental change (Partridge 1993). It is a unique environmental phenomenon since the wellpreserved Crater is the only example of a lake occupying a meteorite impact crater in Southern Africa. Zooplankton and fish are prevented from colonising the lake because of nocturnal deoxygenation. The few species of invertebrates found in the lake (nematode worms and brine flies) are confined to the surface. Several species of waders and water-fowl are found around the edges of the lake. A single species of salt-tolerant sedge grows in and along the lowsalinity feeder stream from the artesian spring. Tswaing is situated in an ecological region known as the sourish-mixed bushveld. For many years this ecological system had a bad reputation for its poor agricultural potential, mainly due to the great variation in the palatability of grass types and the occurrence of toxic plants. The result was that areas with more palatable grasses and less toxic plants were inevitably overgrazed. Overgrazing and the elimination of the tastier grass types increased the occurrence of more sour and less palatable grasses (http://www.nfi.org.za/Tswaing).
The surroundings around Tswaing were probably periodically inhabited by early Stone Age people 500000 years ago. At Tswaing stone artefacts from the Late Stone Age, brought there by the ancestors of the San (Bushman) people who lived from 30000 to 2000 years ago, have been found. The first farmers using iron implements, ancestors of the present indigenous people, migrated to South Africa about 1750 years ago. The migration by Iron Age communities to the South African highveld (where Tswaing is located) took place in more recent times, about 800 to 900 years ago. Shards from decorated clay vessels, found on the crater floor, indicate that the latter were early Sotho- or Tswana-speaking communities, known as the Moloko. Similar pot fragments have been found in the Waterberg mountain range, about $60 \mathrm{~km}$ north of Tswaing. Soon after the departure of the Matebele in the early 1830s, the Tswaing area was claimed by another group of settlers, the Voortrekkers. They were white Afrikaner farmers, who had emigrated from the Eastern Cape region to the present-day Kwazulu-Natal and the interior. The Voortrekkers regarded the land abandoned by the Matabele, whom they eventually defeated in 1837 , as land available for permanent colonial settlement. In the 1850s these farmers divided the region north of the Magaliesberg into huge farms. The Crater became the centre of one such farm, aptly named Zoutpan (Dutch for salt pan). During the 1890s, when Zoutpan was surveyed properly for the first time, its northeastern quarter became a separate farm, named Uitspan (outspan, or resting-place). During the 19th century, Tswaing was one of the main sources of natural salt for the region north of Pretoria, which was established in 1855 as the capital of the Transvaal Boer Republic. Because of its economic importance, Zoutpan became state property in 1876 (http://www.nfi.org.za/Tswaing).

More lately the Crater has been developed as an enviro-museum, the first of its kind in South Africa (Moolman \& De Jongh 1995). A trail was also previously developed in the Crater with the aim of affording tourists the opportunity to explore it. The environmental education potential of Tswaing Meteorite Crater lies in its potential as a popular environmental education community resource centre providing opportunities for recreation and environmental education. It could also generate revenue for the local community through tourism (De Jong 1995). To do justice, however, to the ideal of 'for the people, by the people', community participation and empowerment are key elements in the development and management of the Tswaing Meteorite Crater opportunity (De Jong 1995). 


\section{Identifying an environmental education pro- gramme}

The Tswaing Meteorite Crater trail provides an opportunity to involve diverse communities living around the Crater in the development of relevant environmental education programmes. It was proposed that contextualised and relevant environmental education could be presented to suit the educational, social, economical, cultural, physical and political environments of the community in which it would operate. This could be done by the development of an environmental education programme, based on the Crater trail, which could be used by teachers, environmental education officers and tour guides.

The development of the aforementioned programme would provide the community with an opportunity to become involved in developing outcomes-specific programmes for learners. This entails incorporating personal experience, participatory and discovery activities to enable the community to experience the Tswaing Meteorite Crater environment in its multiplicity, not only as a natural resource to be utilised, but also to be nurtured and developed responsibly and sustainably. An attempt would also be made to provide opportunities for learners and the community to broaden their sense of understanding and appreciation of the broader environment in which a unique natural resource, like Tswaing Meteorite Crater, exists.

\section{Results}

\section{Situation analysis}

When one considers getting a local community involved in a joint venture, it is important to ascertain how the community chooses to define participation, because this will determine which level of participation will satisfy the environmental education goals of the programme. It is necessary, therefore, to learn more about the community concerned beforehand. According to Swanepoel (1989), existing obstacles concerning community development, such as illiteracy, customs and traditions, dependency and apathy could be encountered. Swanepoel (1989) further states that the very reason for community development acts as an obstacle to successful projects. The poverty of the people and their lack of self-sufficiency and selfreliance make it very difficult to involve them in development efforts.

The following aspects were considered as general guidelines during the situation analysis:

- The first decision of a person who wants to work in a community is to decide how and when to enter the community. The first entrance into a community may be the last opportunity to gain its trust. Initial mistakes might influence the researcher, facilitator or community worker permanently.

- Most community workers do not have a specific choice of community because they work for an organisation. They should, therefore, work extensively at establishing their own acceptability in the community and the image of their organisation.

- If the community worker has a choice of community, the strategy of approaching the community should be carefully planned beforehand.

- It is useful if the community worker has some existing link with the community. It is also extremely helpful to stay in the community itself.

- It is valuable for community workers to choose their own initial contacts, but sometimes the organisation they work for prescribes these contacts.

- Community development can be a learning process only if people really participate (Swanepoel 1989).

- The community must be made aware of the exact purpose of the project: Which needs should be addressed and who should address them?

Community contact at Tswaing had already been established through community forums and meetings. These structures were operating functionally and positively and the environmental education project could make use of them rather than attempting to establish new links and associations with the communities. Using these structures, the community was made aware of the purpose of the project, ascertaining their role in the project and 
the needs it would attempt to address. Direct participants of the community included forum members, tour guides, teachers and learners, Tswaing Museum staff and construction workers from the local community. The broader "community" was indirectly involved through the utilisation of Tswaing facilities and programmes.

After having made contact with the community, the next most important step was to assess the community structures. It was necessary to obtain both abstract and physical information. Abstract information included aspects such as the attitudes, beliefs, religion, habits and culture of the community. Physical structures included the population size, housing facilities, job opportunities, school facilities, transport, etc. Swanepoel (1989) also regards the determining of family ties in the community as a very important step, because the family is a basic social structure (abstract structure) in communities. The researchers had to be aware of some of the subtleties of the abstract structures such as political positions to enable them to be fexible. It was useful to be familiar with physical structures to determine which role the researcher could play in the improvement of the community's physical needs.

\section{Implementation of initial environmental education project}

The environmental education project at Tswaing Meteorite Crater was carried out in two main phases and was part of a larger project conducted by the former National Cultural History Museum. The initial project (co-ordinated by an independent researcher) comprised two elements, namely a teacher's guide and tourist guides. The teacher's guide was compiled to give the teacher adequate information about Tswaing Meteorite Crater which had been obtained from previous research reports and articles. It included instructions on how to use the guide, details of the trail and possible activities that could be carried out along a specific section. These included preliminary- and follow-up activities. It also contained safety hints, materials needed for the activities, techniques that could be used on the trail, examples of worksheets and lists of fauna and flora found in the vicinity of the Crater. Teachers could select activities from the teacher's guide and design their own programmes for their learners. In conjunction with the compilation of the teacher's guide, a programme was structured and tour guides from the local communities were trained to assist the teacher in facilitating the school groups during the programme. This created jobs for the local communities, which is one of the main purposes of a community project.

To ensure that both abstract and physical information had been included in the manual, the development of the teacher's guide and the training of the tour guides were done in close consultation with the parents, teachers and learners from the communities, as well as subject specialists. These consultations were done through regular forum meetings and training sessions at Tswaing. Local inputs shaped both the training phase of the tour guides and the development of the teacher's guide. Three trial groups of learners (grades 1 to 6 ; 7 to 9 ; and 10 to 12 ) traversed the trail assisted by the tour guides. It became clear from this exercise that identifiable results of group dynamics come into play and cultural and language differences become significant influencing factors. Different environmental features had different meanings to different groups. The different language groups used different names for the same object and had a variety of folk stories to tell about certain objects. These were incorporated into the project. This exercise helped to enrich the project by lending an indigenous flavour and helped to incorporate abstract information. To cope with groups that could represent up to nine different language groups, individuals in a group were used as interpreters. It became evident from the pilot group that adaptations had to be made regarding walking distance, time spent on activities and making activities suitable for the different grades. After having made all the necessary changes to the project, it was launched in 1996. 
A major local community issue soon emerged, namely that 300 learners of different age groups from surrounding schools arrived at Tswaing Meteorite Crater conservation area unprepared for the programmes they were about to experience. These groups had no set outcomes or selected activities. Thus, it was very difficult for the limited number of Tswaing staff who only had basic environmental education skills, to accommodate these groups effectively. This had to be taken into consideration during the next phase of the research.

\section{Implementation of second phase of environ- mental education project}

At the end of 1996 a more structured approach to the project was adopted. The project manager approached an environmental education specialist from the University of South Africa middle 1997 to set up a team of environmental educationists who could help with extending the environmental education programmes at Tswaing Meteorite Crater conservation area. This was subsequently done and representatives from the University of South Africa, Vista University, the South African College for Teacher Education and staff of the former National Cultural History Museum met to start the process. It was emphasised that:

- all the communities living around the Crater should be consulted and included in the development of the extended programmes;

- all programmes should adhere to the new outcomes-based education system;

- the crater should form the focal point of the programmes;

- the entire education system should be covered (all the phases and learning areas); and

- the programmes would operate along the trail.

A chairperson for the educational committee was elected at a subsequent meeting and commissioned to proceed with the development of programmes. The educational committee was extended to include other role players such as the Gauteng Department of Nature Conservation, teachers from communities around Tswaing, as well as community members. The committee explored the trail at Tswaing Meteorite Crater twice.

Sixteen special features concerning the trail were identified and grouped together into 10 stations. This was further defined into six possible programmes that could be conducted along sections of the longer trail. Small teams, including teachers from local schools and community members, worked on the development of these programmes, keeping in mind the different phases and learning areas of the new outcomes-based curriculum, adaptability and exchangeability. Moreover, guides had to be trained to facilitate the programmes.

A pilot run of the 57 activities in the six programmes was carried out over four days. On day one the activities were piloted for the foundation phase (grades 1 to 3 ), day two for the intermediate phase (grades 4 to 6), day three for the senior phase (grades 7 to 9) and day four for grades 10 to 12 which form part of the further education phase of the National Qualifications Framework. The learners who were used had been invited from schools in the local area, together with their teachers, to ensure that the target community assisted in shaping the programme and establishing a true learning process. The teachers were included to ensure an element of certainty in the groups and to facilitate communication.

This piloting exercise was experienced positively by the learners, as well as the teachers. However, it took a while for both groups to become comfortable with the programme presenters, because they were unfamiliar with the people, methods and approaches utilised. However, the pilot groups settled down after a while. The programme developers also learned a great deal and further principles emerged which had to be kept in mind when developing an environmental education programme for a specific community and environment.

It became clear that: 
- the teachers and learners were not familiar with the concept environmental education;

- the background knowledge of the teachers and learners were not what the environmental education programme developers had assumed it to be;

- language and terminology differences existed;

- time was a crucial factor;

- the mastering of specific skills required repetition;

- the environment was perceived mainly as physical; and

- cross-curricular activities were foreign to them.

These points merely serve to reinforce the necessity of doing research and consulting with the community in question prior to developing programmes. Projects need to be contextualised socially, politically, culturally, educationally and economically within the environment in which the project is to be conducted. This result was no different from the first phase of the project, but the project developers still redesigned their activities to try and accommodate the above-mentioned aspects. These revised activities have been incorporated into a publication which is currently used by the environmental education officer at Tswaing to facilitate different school groups regarding environmental education.

\section{Issues emerging from the case study}

The Tswaing environmental education project was a case study of an attempt to put environmental education research into practice by involving local communities in developing environmental education programmes in their environment. It was found that in the development of similar programmes a number of issues have to be considered, namely, the target audience (community) of the programme, the training of tour guides, educational officers and teachers, the development of specific stations and the writing of the teacher's guide.
Regarding the target audience, it is essential to:

- $\quad$ keep in mind the way in which the target audience interprets the local and broader environment because of indigenous abstract information which is not known to the developer;

- use the local community in as many aspects of the programme development as possible in order to ensure that the people participate in the development of the direction and context of the programme;

- use the local community to help construct the buildings and structures necessary for the project, thus contributing to the well-being of the community; to tell stories recorded on tape and to act as tour guides, and so be involved and be part of the action;

- $\quad$ keep in mind the indigenous background knowledge of the community;

- keep in mind the local community's understanding of environmental education;

- develop pre-visit activities for the programme users to familiarise them with the purpose of the programme and to obtain information from them which could influence the progress of the programme;

- develop follow-up activities for programme users to help the developer to assess the success of the activity; and

- keep in mind language and terminology differences and to incorporate these into the programme.

The abovementioned principles correspond with the supporting objectives of Goal 5 of the White Paper on Environmental Management (Republic of South Africa 1998).

The facet of training is important for preventing possible misunderstandings between the developer and the community. Possible strategies are to:

- train project developers about the customs, traditions, fears and literacy levels of the local community in which they are about to work; 
- train local tour guides/educational officers to help facilitate programmes;

- train local teachers how to use programmes;

- train staff to understand environmental education and its underlying principles;

- provide training in outcomes-based education for teachers and tour guides/educational officers;

- provide extensive background information rather than limited information; and

- use community leaders to assist with training in order to localise and contextualise the programme.

If stations or special features are a facet of a project, the following points should be considered:

- Use members from the local community to do construction work and to build toolboxes and equipment needed at the stations. This assists the community in participating actively in the project and provides them with a welcome income.

- Use the stations which are relevant to the teachers' requests/outcomes.

- Keep safety aspects in mind.

- Incorporate local information, for example use local persons to tell stories, incorporating local customs and traditions.

- Give stations locally-accepted and understood names rather than number features, as this creates an indigenous and familiar environment.

- Use only one feature rather than too many.

- Provide facilities such as water, recycling and toilet points to meet the physical needs of the community.

If a teacher's guide forms part of a project, the following aspects should be considered:

- use people from the local community to assist with compiling activities and thus eliminate possible biased interpretations;

- incorporate local interpretation(s) and terminology into the activities;

- allow for freedom of interpretation and flexibility when programmes are used by different groups/communities.

\section{Conclusion}

According to Makumbe (1996), Robinson \& Shallcross (1998) and Pausewang et al. (1990), there is a definite need for development in communities in developing countries. Knowledge gained from work in these communities could inform more developed countries on issues such as who should participate in programme development, and to which extent. The Tswaing Meteorite Crater case study shed light on this particular statement because of the participation of a diverse group of role players from the local area (teachers, learners, community leaders and other individuals) and the surrounding environment (universities and the former National Culture History Museum).

During the Tswaing environmental education project, research insights were put into practice with success to a large extent. It would, however, need to be assessed whether the local communities have benefited through the environmental education programmes in the long term and whether these benefits can actually sustain the Tswaing environment, thus satisfying conservation, educational and developmental objectives. Through the Tswaing research project and its unique physical environment and mixture of diverse communities, certain principles were identified from the two development phases for community-based environmental education programmes which could accomplish the abovementioned. It is envisaged that these principles can be applied to similar programmes in other communities. To understand the society or community one is working with, one needs to understand the space or environment in which the community operates (Bird 1989). However, it is important to realise that these principles are flexible and should be adapted to the specific environment and communities where they are being implemented, to make environmental education programmes sufficient and beneficial to the community. 


\section{Acknowledgements}

The former National Cultural History Museum is acknowledged for making this project possible. The settlements in and around Tswaing Meteorite Crater are thanked for their participation in the project and their contribution to this article.

\section{References}

BIRD, J. 1989. The Changing Worlds of Geography: A critical guide to concepts and methods. Oxford: Claredon Press.

De Jong, R.C. 1995. The Tswaing Crater Museum. Pretoria: National Cultural Historical Museum.

FIEN, J. 1993. Education for sustainable living: An international perspective on environmental education. Southern African Journal for Environmental Education 7:20.

http://www.nfi.org.za/Tswaing.

http://www.nfi.org.za/Tswaing/map.htm.

HuCKLE, J. 1991. Education for sustainability: Assessing pathways to the future. Australian Journal of Environmental Education 7:43-62.

KHAN, S. 1994. How people get power. Washington: NASW Press.

LOUBSER, C.P. 1998. Empowering rural communities through environmental education and research: Draft report. Pretoria: University of South Africa.

Makumbe, J.M. 1996. Participatory development. The case of Zimbabwe. Harare: University of Zimbabwe Publications.

Moolman, H.J. \& R.C. DE Jongh. 1995. Final report of the research project on: The contribution of SITE Museums to the conservation and the interpretation of the environment with special reference to the Tswaing Crater Museum. Internal report. National Cultural History Museum. Pretoria.

MosidI, S.M. 1999. Environmental education in curriculum 2005: A case study in the Northern Cape. Johannesburg: Rand Afrikaans University.
Nelvhalani, E. \& S. Mphaphuli. 2000. Environmental Educators Networking for Professional Development: A case study of the Northern Province, Far North Region. Case study 4. Educating for Social Change. Case studies of changing practices in South African Tertiary Institutions, Australian Institutional Links Programme.

PARTRIDGE, T. 1993. Environmental data relative to the establishment of a museum at the Pretoria Salt Pan. Pretoria: National Cultural Historical Museum library. (Ta17.)

Pausewang, S., F. Cheru, S. Brune \& E. Chole. 1990. Ethiopia. Rural Development Options. London: Zed Books Ltd.

Republic of South Africa. 1995. White Paper for Education and Training. Pretoria: Department of Education, Government Printer.

Republic of South Africa. 1998. White Paper on Environmental Management. Pretoria: Department of Environmental Affairs and Tourism, Government Printer. 395(18894).

Robinson, J. \& T. Shallcross. 1998. The socioecological crisis and education for sustainable living: Is an essentialist's standpoint possible? Pp. 23-28. In: LaUBSCHER, C.P. Proceedings of the International Best of Both Worlds Conference at Dikhololo, Brits, September 1998. Pretoria: University of South Africa.

Sustainability EdUCATION IN EURopean PRimary ScHOOLs. 1998. Creating a better environment in our school. Edinburgh: Moray House Institute.

Sмyтне, J.C. 1995. Environment and education: a view of a changing scene. Environmental Education Research 1(1):3-20.

Stevenson, R.B. 1993. Becoming compatible: curriculum and environmental thought. Journal of Environmental Education 24(2):4-9.

SwANEPOEL, H. 1989. Community development. Putting plans into action. Cape Town: Juta .

VilJoen, H.J. 1993. Environmental education and open spaces. Parke en Rekreasiebestuur 51(4): 22-24. 